\title{
Tambacus (Colossoma macropomum x Piaractus mesopotamicus) alimentados com rações artesanais de macaxeira e soja
}

\author{
Meyer, G. ${ }^{1}$; Corrêa, R.O. ${ }^{\circledR}$; Martins-Junior, H. ${ }^{2}$; Silva, R.M. ${ }^{3}$; Costa, S.M. ${ }^{4}$ e Santana, M.F.S. ${ }^{5}$
}

\author{
Universidade Federal dos Vales do Jequitinhonha e Mucuri. Unaí. Minas Gerais. Brasil. \\ ${ }^{2}$ Empresa Brasileira de Pesquisa Agropecuária. Belém. Pará. Brasil. \\ ${ }^{3}$ Universidade Nilton Lins/Instituto Nacional de Pesquisas da Amazônia. Manaus. Amazonas. Brasil. \\ ${ }^{4}$ Instituto Federal de Educação, Ciência e Tecnologia do Pará - IFPA. Castanhal. Pará. Brasil. \\ ${ }^{5}$ Centro de Tecnologia da Informação, CTI. Ministério da Ciência, Tecnologia, Inovações e Comunicações. Fortaleza. Ceará. Brasil.
}

\section{PaLAVRAS CHAVE ADICIONAIS}

\section{Manihot esculento.}

Glycine max.

Ganho em peso.

Fósforo.

Metionina.

Peixes.

\section{RESUMO}

O uso de rações artesanais é uma das alternativas que vem sendo discutidas para a viabilização da piscicultura familiar na Amazônia. A adoção desta estratégia, no entanto, requer o emprego de critérios para o balanceamento das rações. O objetivo deste estudo foi investigar o desempenho produtivo de tambacus (Colossoma macropomum x Piaractus mesopotamicus) quando alimentados com rações artesanais à base de macaxeira e farelo de soja, bem como avaliar a necessidade de suplementálas em aminoácidos, energia e macro minerais. Para tanto, 813 juvenis $(48,49 \pm 4,21 \mathrm{~g})$ foram estocados em 15 tanques de concreto com fundo de terra $(48,50 \pm 3,61 \mathrm{~m} 2 \times 0,8 \mathrm{~m})$ e alimentados com cinco diferentes rações, sendo quatro delas artesanais e isoprotéicas $(25 \% \mathrm{~PB})$, a saber: $\mathrm{C} 1$ (macaxeira + farelo de soja + premix; como controle), R1 (C1 + fosfato bicálcico), R2 (Cl + fosfato bicálcico + óleo de soja), R3 (C1 + fosfato bicálcico + óleo de soja + DL-metionina) e C2 (ração comercial extrusada $32 \% \mathrm{~PB}$; utilizada como parâmetro de comparação regional). Após 75 dias, foi detectado o efeito positivo $(\mathrm{P}<0,05)$ da suplementação de fosfato bicálcico sobre o ganho em peso, conversão alimentar, taxa de crescimento específico e taxa de eficiência protéica (TEP). Não foram detectados efeitos positivos da adição de óleo de soja ou de DL-metionina. Similarmente, não foram detectadas diferenças significativas entre as rações artesanais suplementadas com fosfato bicálcico (R1, R2 e R3) e C2, com exceção da TEP, que foi menor para os peixes alimentados com C2. Os resultados obtidos sugerem que é possível a criação de juvenis de tambacu com rações artesanais à base apenas de macaxeira, farelo de soja, premix e fosfato bicálcico, sem que haja prejuízos produtivos.

\section{Tambacus (Colossoma macropomum x Piaractus mesopotamicus) fed cassava and soybean meal artisanal feed}

\begin{abstract}
SUMMARY
The usage of artisanal feed is an alternative that is been discussed to support household fish culture in Amazonia. Employing this strategy, however, require the adoption of some criteria for adjusting feed nutrient balance. The purpose of this study was to investigate juvenile tambacu (Colossoma macropomum $\times$ Piaractus mesopotamicus) performance when fed cassava and soybean meal artisanal feed, as well to evaluate the need of its supplementation to fulfill fish amino acids, energy and macro minerals requirements. For this, 813 juveniles $(48.49 \pm 4.21 \mathrm{~g})$ were stocked in 15 reinforced concrete ponds (earthen ground; $48.50 \pm 3.61 \mathrm{~m}^{2} \times 0.8 \mathrm{~m}$ ) and fed five different diets, in which four of them were artisanal, formulated to be isoproteic $(25 \% \mathrm{CP}$ ), as follow: $\mathrm{Cl}$ (cassava + soybean meal + premix; as control), $\mathrm{R} 1(\mathrm{Cl}+$ dicalcium phosphate), $\mathrm{R} 2(\mathrm{Cl}+$ dicalcium phosphate + soybean oil), R3 $(\mathrm{Cl}+$ dicalcium phosphate + soybean oil + DL-methionine), and C2 (32\%PB commertial extruded feed; as regional comparison parameter). After 75 days, a positive effect of dicalcium phosphate supplementation were detected $(\mathrm{P}<0.05)$ for weight gain, feed conversion, specific growth rate and protein efficiency ratio (PER). The effects of soybean oil or DL-methionine additions were not detected. Similarly, no significative differences were detected among the supplemented dicalcium phosphate artisanal feed (R1, R2 e R3) and C2, except for PER, that was lower for fish fed C2. These results have shown that there are no productive losses when juvenile tambacu are fed artisanal diets, containing only cassava, soybean meal, premix and dicalcium phosphate.
\end{abstract}

\section{INTRODUÇÃO}

A região amazônica apresenta grande potencial para a criação de peixes de água doce, em função de sua temperatura ambiental elevada e grande disponibilidade hídrica. Entretanto, fatores como as grandes distâncias geográficas, intrínsecas à região, e a consequente dificuldade para a obtenção de insumos têm sido os 
principais entraves para a expansão da piscicultura local. Nesta perspectiva, o uso de rações artesanais, confeccionadas nas próprias unidades de produção, é tido como uma das alternativas para transpor parte desta problemática, particularmente em relação à piscicultura familiar.

O uso de rações artesanais, no entanto, está associado a duas limitações principais. A primeira refere-se ao fato de que seus grânulos afundam e, por isso, podem proporcionar piores índices de conversão alimentar (Tacon et al., 2011; Kubitza, 2003), além de exigir um manejo alimentar mais cuidadoso. A segunda está relacionada à logística de aquisição de ingredientes para sua confecção, uma vez que a obtenção de rações balanceadas pode exigir, além de macro ingredientes, o emprego de alguns suplementos, tais como minerais, aminoácidos e aditivos (Tacon, 2009).

A partir dessas limitações, nossa hipótese central é a de que o farelo de soja (Glycine max) pode ser utilizado como único macro ingrediente proteico para possibilitar a criação artesanal do tambacu (Colossoma macropomum x Piaractus mesopotamicus), híbrido do cruzamento entre a fêmea de tambaqui e o macho de pacu, uma das principais espécies criadas na região amazônica em função de seu rápido crescimento (Hashimoto et al, 2011). Uma segunda hipótese é a de que, a macaxeira (Manihot esculenta), ingrediente abundante em todas as épocas do ano nas unidades de produção familiar dessa região, em consórcio com o farelo de soja, seria capaz de atender às exigências energéticas desta espécie, de modo a possibilitar o uso de dietas artesanais confeccionada essencialmente com estes dois macroingredientes.

$\mathrm{O}$ uso de rações artesanais à base de macaxeira e farelo de soja ainda não foi investigado para quaisquer espécies amazônicas, muito embora estes ingredientes, isoladamente, já tenham sido testados para o tambaqui, Colossoma macropomum (Van Der Meer, 1997a; Lochmann et al., 2009), com bons resultados. Assim, os objetivos do presente estudo foram: investigar o desempenho produtivo de juvenis de tambacu quando alimentados com ração artesanal à base de macaxeira, farelo de soja e premix; e avaliar a necessidade de suplementação desta ração com fosfato bicálcico, óleo de soja e DL-metionina, para balanceá-la em macro minerais, energia e aminoácidos, respectivamente.

\section{MATERIAL E MÉTODOS}

\section{ENSAIO DE CRESCIMENTO}

O experimento foi conduzido em 2011, na Estação de Piscicultura da Embrapa Amazônia Oriental, localizada no município de Belém, Pará, sob as coordenadas $1^{\circ} 25^{\prime} 38^{\prime \prime} \mathrm{S}$ e $48^{\circ} 25^{\prime} 11^{\prime \prime} \mathrm{O}$, devidamente aprovado pela Comissão de ética no uso de animais da Instituição (001.2017). Antes de sua execução, 813 juvenis de tambacu, obtidos de uma piscicultura comercial, foram estocados em 15 tanques de concreto com fundo

Tabela I. Formulação e composição das rações experimentais, \% da matéria seca (Formulation and composition of the experimental feed, \% dry matter).

\begin{tabular}{|c|c|c|c|c|c|}
\hline \multirow[t]{2}{*}{ Ingredientes } & \multicolumn{5}{|c|}{ Rações } \\
\hline & Controle 1 & 1 & 2 & 3 & Controle $2^{\mathrm{a}}$ \\
\hline Farelo de soja & 52,34 & 52,88 & 53,85 & 53,90 & --- \\
\hline Macaxeira & 47,16 & 44,37 & 39,40 & 39,15 & --- \\
\hline Premix ${ }^{b}$ & 0,50 & 0,50 & 0,50 & 0,50 & --- \\
\hline Fosfato bicálcico & --- & 2,25 & 2,25 & 2,25 & --- \\
\hline Óleo de soja & --- & --- & 4,00 & 4,00 & --- \\
\hline DL-metionina & --- & --- & --- & 0,20 & --- \\
\hline \multicolumn{6}{|l|}{ Composição } \\
\hline Matéria seca original & 88,35 & 94,10 & 95,75 & 96,04 & 92,51 \\
\hline Proteína bruta & 27,83 & 25,38 & 25,84 & 26,45 & 37,15 \\
\hline Extrato etéreo & 0,74 & 0,68 & 3,72 & 3,22 & 6,42 \\
\hline Fibra bruta & 7,47 & 7,49 & 6,57 & 6,73 & 5,85 \\
\hline Cálcio & 0,26 & 0,75 & 0,77 & 0,73 & 0,99 \\
\hline Fósforo & 0,41 & 0,81 & 0,81 & 0,82 & 0,90 \\
\hline Cinzas & 4,99 & 6,36 & 6,32 & 6,27 & 12,85 \\
\hline $\mathrm{ENN}^{\mathrm{c}}$ & 58,97 & 60,08 & 57,54 & 57,33 & 37,71 \\
\hline Energia brutad $\left(\mathrm{MJ} \mathrm{kg}^{-1}\right)$ & 16,99 & 16,44 & 17,30 & 17,22 & 17,63 \\
\hline
\end{tabular}

a Ração comercial extrusada, 32\% PB, 4-6 mm (Grupo Guabi, Campinas, SP).

${ }^{\mathrm{b}}$ Premix mitamínico mineral (Nutron Alimentos, Campinas, SP). Composição por kg do produto: ácido fólico 250 mg, ácido pantotênico $5000 \mathrm{mg}$, biotina $125 \mathrm{mg}$, cobalto $25 \mathrm{mg}$, cobre $2000 \mathrm{mg}$, colina $15000 \mathrm{mg}$, ferro $13820 \mathrm{mg}$, iodo $100 \mathrm{mg}$, manganês $3750 \mathrm{mg}$, niacina 5000 $\mathrm{mg}$, selênio $75 \mathrm{mg}$, vitamina A (acetato de retinol) $1000000 \mathrm{UI}$, tiamina $1250 \mathrm{mg}$, vitamina $\mathrm{B}_{12} 3750 \mathrm{mcg}$, riboflavina $2500 \mathrm{mg}$, piridoxina $1875 \mathrm{mg}$, vitamina C $42000 \mathrm{mg}$, vitamina $\mathrm{D}_{3} 500000 \mathrm{UI}$, vitamina $\mathrm{E}$ (acetato de tocoferol) $20000 \mathrm{UI}$, vitamina $\mathrm{K}_{3} 500 \mathrm{mg}$, zinco $17500 \mathrm{mg}$.

${ }^{c}$ Extrativo não nitrogenado, onde EEN = $100-(\% \mathrm{~PB})-(\%$ de extrato etéreo $)$ - (\% de cinzas $)$ - (\% de fibra bruta).

dEnergia bruta calculada a partir das porcentagens de carboidratos, proteínas e lipídios das dietas, utilizando-se os valores de 17,20;23,60 e39,50 MJ para cada kg destes nutrientes, respectivamente (Bureau et al., 2002). 
de terra, dotados de abastecimento individual (vazão aproximada de $20 \mathrm{~L} \mathrm{~min}^{-1}$ por tanque) e área média de $48,50 \pm 3,61 \mathrm{~m}^{2}$. A densidade de estocagem adotada foi de 1,11 peixes por $\mathrm{m}^{2}$.

Os peixes foram aclimatados às condições experimentais durante 15 dias, sendo alimentados duas vezes ao dia com ração comercial extrusada (32\% de proteína bruta, PB). Após este período, os peixes foram pesados individualmente (peso médio de 48,49 \pm 4,21 g) e alimentados durante 75 dias, duas vezes ao dia (8h00 e 16h00), com cinco diferentes rações, cada uma constituindo um tratamento (cinco tratamentos, três repetições por tratamento; delineamento inteiramente ao acaso). A taxa de alimentação adotada foi de 3\% do peso vivo, sendo que a cada 15 dias os peixes foram submetidos a biometrias parciais (Figura 1), o que permitiu o ajuste dessa taxa em função de seu crescimento.

\section{FORMULAÇÃO E CONFECÇÃO DAS RAÇÕES EXPERIMENTAIS}

A formulação e a composição das rações experimentais estão apresentadas na Tabela I. Estas foram formuladas a partir da prévia determinação da composição de seus ingredientes (tubérculos de macaxeira com casca e farelo de soja; Tabela II) e utilizando-se o software Super Crac 5.4 (TD Software, Viçosa-MG). As exigências nutricionais do tambacu foram estimadas com base nos estudos e revisões de Camargo et al. (1998), Vidal-Júnior et al., 1998, Fracalossi (2002), Bicudo et al. (2005) e Abimorad et al. (2007). Para os nutrientes que não foram encontradas exigências estabelecidas, utilizaram-se as informações referentes à tilápia do Nilo, Oreochromis niloticus, sintetizadas no NRC (1993).

A partir da estimativa, uma ração controle 1 foi formulada para atender à exigência protéica do tambacu. Três outras rações, 1, 2 e 3, foram formuladas para,

Tabela II. Composição dos ingredientes experimentais, \% da materia seca (Composition of the experimental feedstuffs, \% dry matter).

\begin{tabular}{lcc}
\hline \multirow{2}{*}{ Composição } & \multicolumn{2}{c}{ Ingredientes } \\
\cline { 2 - 3 } & Farelo de soja & Macaxeira $^{\mathrm{a}}$ \\
\hline Matéria seca original & 88,69 & 30,09 \\
Proteína bruta & 51,32 & 9,84 \\
Extrato etéreo & 1,94 & 2,49 \\
Fibra bruta & 9,80 & 9,70 \\
Cinzas & 2,40 & 1,30 \\
Cálcio & 0,35 & 0,60 \\
Fósforo & 0,71 & 0,20 \\
ENN & 34,54 & 76,67 \\
Energiac $^{\text {(MJ kg }}{ }^{-1}$ ) & 18,82 & 16,28 \\
\hline
\end{tabular}

a Macaxeira, Manihot esculenta; tubérculos com casca, obtidos no município de Irituia-PA, colhidos após um ano de cultivo, medindo em média $30 \mathrm{~cm}$.

${ }^{\mathrm{b}}$ Extrativo não nitrogenado, onde EEN = $100-(\% \mathrm{~PB})-(\%$ de extrato etéreo $)$ - ( $\%$ de cinzas $)$ - ( $\%$ de fibra bruta).

c Energia calculada a partir das porcentagens de carboidratos, proteínas e lipídios das dietas, utilizando-se os valores de 17,20; 23,60 e 39,50 MJ para cada kg destes nutrientes, respectivamente (Bureau et al., 2002). progressivamente, atender às exigências em macrominerais, energia e aminoácidos, também conforme a estimativa das exigências. Para tanto, a ração 1 foi suplementada com fosfato bicálcico, a ração $2 \mathrm{com}$ fosfato bicálcido e óleo de soja, e a ração 3 com fosfato bicálcico, óleo de soja e DL-metionina. Ao final, foram constituídas 4 rações isoprotéicas (25\% de proteína bruta, PB). Adicionalmente, foi incluída, como um segundo controle, uma ração comercial extrusada $(32 \% \mathrm{~PB}$, 4-6 mm; Grupo Guabi, Campinas, SP), para servir de parâmetro de comparação regional (Nordeste Paraense), já que, na região, juvenis de tambacus são criados com este tipo de ração.

As rações 1, 2, 3 e controle 1 foram confeccionadas obedecendo-se às seguintes etapas: (i) lavagem dos tubérculos de macaxeira com casca; (ii) ralagem da macaxeira em ralador elétrico; (iii) mistura manual dos ingredientes secos; (iv) adição de óleo aos ingredientes secos; (v) mistura da macaxeira ralada à pré-mistura seca adicionada de óleo; (vi) confecção de grânulos entre 3,5 e $5 \mathrm{~mm}$ utilizando-se moedor de carne (PB22, Beccaro, Rio Claro-SP); (vii) secagem a $65^{\circ} \mathrm{C}$ em secador artesanal (caixa de alvenaria medindo $1 \times 1 \times 2 \mathrm{~m}$ acoplada a soprador de ar quente Hotwind, 3700W, Leister), durante $6 \mathrm{~h}$; (viii) embalagem e armazenamento $\mathrm{a}-20^{\circ} \mathrm{C}$ até o momento de utilização. A composição de todas as rações foi determinada posteriormente, seguindo-se a metodologia da AOAC (2000).

Durante o período experimental foram registrados dados para o cálculo de cinco indicadores de desempenho, a saber: ganho em peso $(\mathrm{GP}=$ peso final - peso inicial), taxa específica de crescimento [TCE = $100($ ln peso final - ln peso inicial) dias ${ }^{-1}$, conversão alimentar $\left[\mathrm{CA}=(\right.$ consumo $\left.)(\text { ganho em peso })^{-1}\right]$, taxa de eficiência proteica $[$ TEP $=$ (ganho em peso) (consumo em proteína $)^{-1}$ ] e sobrevivência. Seis parâmetros indicadores de qualidade da água também foram medidos e registrados. A concentração de oxigênio dissolvido e a temperatura (oxímetro multifuncional YSI 55) foram medidas diariamente, nos horários de alimentação, e o pH, concentrações de amônia e nitrito (kits colorimétricos Acqua Imagem, Jundiaí-SP) e condutividade (condutivímetro Q405B, Quimmis, Diadema-SP) semanalmente.

\section{ANÁLISE ESTATÍSTICA}

Os dados de peso inicial, GP, TCE, CA, TEP e sobrevivência foram submetidos aos testes de normalidade e de variâncias iguais, bem como à análise de variância, adotando-se o nível de significância de 5\%. Nos casos de detecção de diferença significativa entre tratamentos, as médias foram comparadas pelo teste de Tukey (Steel et al., 1997). Os dados em porcentagem foram previamente transformados em arco-seno. Para efeitos de possibilitar a verificação da influência de cada ingrediente separadamente, utilizou-se adicionalmente o teste t-student, também adotando-se o nível de significância de $5 \%$.

\section{RESULTADOS E DISCUSSÃO}

As médias ( \pm desvio padrão) de temperatura, concentração de oxigênio dissolvido, $\mathrm{pH}$, amônia, nitrito e 
Tabela III. Desempenho de juvenis de tambacu alimentados com rações artesanais à base de macaxeira e farelo de soja, suplementadas com fosfato bicálcico, óleo de soja e/ou metionina sintética, após 75 dias $^{\mathrm{a}}$ (Performance of juvenile tambacu fed cassava and soybean meal artisanal feed, enriched with dicalcium phosphate, soybean oil and/or DL-methionine, after 75 days $^{\mathrm{a}}$ ).

\begin{tabular}{|c|c|c|c|c|c|c|}
\hline \multirow[t]{2}{*}{ Indicadores } & \multicolumn{4}{|c|}{ Rações } & \multirow[b]{2}{*}{ Controle 2} & \multirow[b]{2}{*}{ Valor $\mathrm{P} e$} \\
\hline & Controle 1 & 1 & 2 & 3 & & \\
\hline Peso inicial (g) & $48,23 \pm 1,71$ & $49,00 \pm 2,11$ & $51,10 \pm 3,44$ & $48,03 \pm 2,00$ & $46,13 \pm 0,87$ & 0,625 \\
\hline Ganho em peso $(\mathrm{g})$ & $81,22 \pm 3,48_{b}$ & $111,70 \pm 2,07_{\mathrm{a}}$ & $112,19 \pm 2,29_{\mathrm{a}}$ & $119,77 \pm 11,9_{a}$ & $117,12 \pm 2,32_{\mathrm{a}}$ & 0,005 \\
\hline TCE $(\%)^{\mathrm{b}}$ & $1,32 \pm 0,01_{b}$ & $1,58 \pm 0,03_{a}$ & $1,55 \pm 0,06_{a}$ & $1,66 \pm 0,05_{a}$ & $1,68 \pm 0,04 a$ & 0,001 \\
\hline Consumo $(\mathrm{g})^{\mathrm{c}}$ & $142,07 \pm 7,51$ & $160,87 \pm 3,23$ & $161,19 \pm 3,82$ & $168,20 \pm 12,3$ & $158,71 \pm 3,63$ & --- \\
\hline Conversão alimentar ${ }^{c}$ & $1,75_{b} \pm 0,02$ & $1,44 \pm 0,03_{a}$ & $1,44 \pm 0,01_{a}$ & $1,41 \pm 0,05_{a}$ & $1,32 \pm 0,04 a$ & 0,001 \\
\hline TEPd & $2,06 \pm 0,03$ & $2,74 \pm 0,066_{a}$ & $2,70 \pm 0,01_{a}$ & $2,68 \pm 0,08_{a}$ & $2,05 \pm 0,07_{b}$ & 0,001 \\
\hline Sobrevivência (\%) & $94,05 \pm 2,59$ & $95,83 \pm 2,15$ & $97,03 \pm 1,03$ & $94,64 \pm 2,06$ & $96,43 \pm 1,57$ & 0,763 \\
\hline \multicolumn{7}{|l|}{ Teste $\mathrm{t}(\text { valor de } \mathrm{P})^{\mathrm{f}}$} \\
\hline & Controle 1 v. Ração 1 & Ração 1 v. Ração 2 & Ração 2 v. Ração 3 & --- & --- & --- \\
\hline Ganho em peso & $0,002^{*}$ & 0,883 & 0,567 & --- & --- & --- \\
\hline $\mathrm{TCE}^{\mathrm{c}}$ & $0,001^{*}$ & 0,682 & 0,276 & --- & --- & --- \\
\hline Conversão alimentar & $0,020^{*}$ & 0,907 & 0,635 & --- & --- & --- \\
\hline TEPe & $<0,001^{*}$ & 0,524 & 0,887 & --- & --- & --- \\
\hline
\end{tabular}

a Médias de três repetições; as médias dentro de uma mesma linha, seguidas de letras diferentes, diferem estatisticamente $(P<0,05$; análise de variância seguida do teste de Tukey). Os dados de consumo não foram submetidos à análise estatística devido à taxa fixa de alimentação. Médias \pm erro padrão da média.

b Taxa de crescimento específico.

c Valores expressos considerando o consumo em matéria seca.

¿ Taxa de eficiência protéica.

e Valor de P na análise de variância.

${ }^{\mathrm{f}}$ Valores seguidos de asteriscos indicam diferença significativa $(P<0,05)$.

condutividade foram de $29,07 \pm 0,28^{\circ} \mathrm{C} ; 5,25 \pm 0,32 \mathrm{mg}$ $\mathrm{L}^{-1} ; 6,18 \pm 1,50 ;<0,6 \pm 0,00 \mathrm{mg} \mathrm{L}^{-1} ; 0,00 \pm 0,00 \mathrm{mg} \mathrm{L}^{-1} \mathrm{e}$ $16,60 \pm 2,03 \mu \mathrm{S} \mathrm{cm}{ }^{-1}$, respectivamente, e não variaram significativamente entre os tratamentos $(\mathrm{P}>0,05)$. Os dados de GP, TCE, consumo, CA, TEP e sobrevivên-

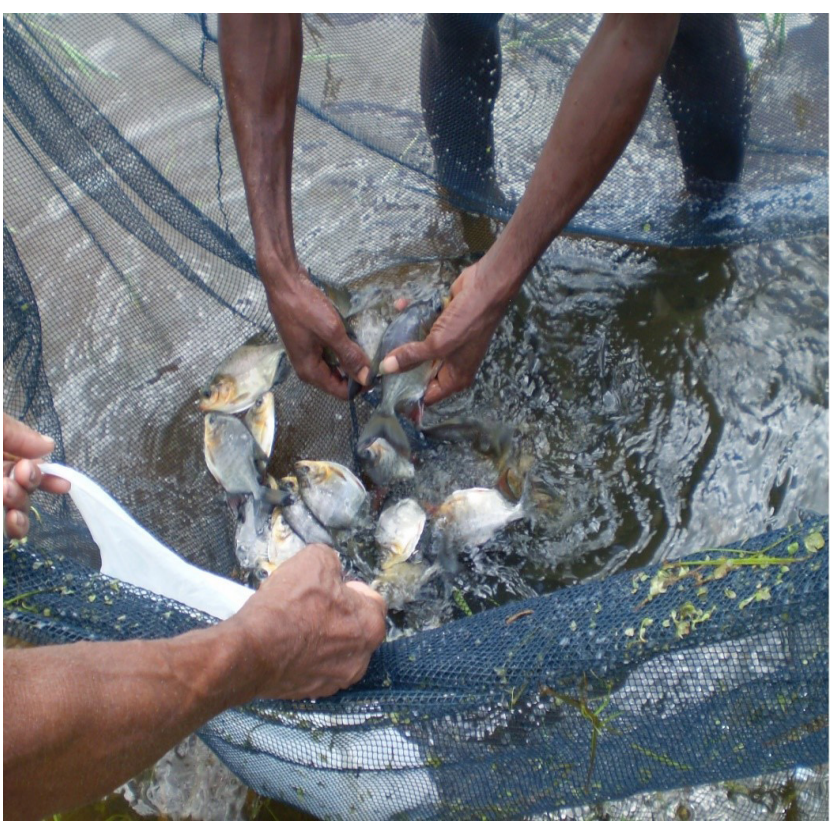

Figura 1. Biometria parcial de tambacus (Colossoma macropomum $x$ Piaractus mesopotamicus) (Tambacus partial biometry (Colossoma macropomum x Piaractus mesopotamicus). cia obtidos no ensaio de crescimento estão expressos na Tabela III. A sobrevivência média dos peixes foi superior aos $94 \%$ e não diferiu entre os tratamentos $(\mathrm{P}>0,05)$.

Os GPs promovidos pelas rações 1, 2, 3 e controle 2 foram significativamente maiores que aquele promovido pela ração controle 1 . A comparação entre as rações 1 e controle 1, a partir do teste t-student (Tabela III), demonstrou o efeito positivo da inclusão de fonte adicional de fósforo $(\mathrm{P})$ e cálcio $(\mathrm{Ca})$ nas rações artesanais. Shao et al. (2008), testando diferentes concentrações de P na dieta de juvenis de Sparus macrocephalus, detectaram que concentrações inferiores a $0,55 \%$ de $\mathrm{P}$ disponível causam a redução do ganho em peso e alterações na composição corporal da espécie. Segundo Lall (2002), recorrendo a estudos de diversos autores, a exigência por este nutriente está quase sempre acima $0,5 \%$ da dieta em P disponível. A partir do teor de $\mathrm{P}$ total da ração controle $1(0,36 \%)$, pode-se inferir que sua concentração de P disponível não supriu a exigência do tambacu, dada a prevalência de ingredientes de origem vegetal. Para Castillo e Gatlin (2015), a suplementação em P é necessária quando são utilizadas rações a base de ingredientes de origem vegetal, nos quais este mineral se encontra sob a forma de fitato, por sua vez não disponível aos peixes em geral. Em relação ao $\mathrm{Ca}$, a exigência por este nutriente é em geral relativamente baixa (inferior a $0,34 \%$ da dieta, dependendo da quantidade disponível na água; NRC, 2011), entretanto, não descartamos a possibilidade do acréscimo deste nutriente ter também favorecido o ganho em peso. De 
Tabela IV. Concentrações energéticas e lipídicas de dietas experimentais que promoveram máximo ganho em peso em juvenis de pacu e tambacu (Dietary energy and lipid concentrations that promoted the maximum weight gain in juvenile pacu and tambacu growth trials).

\begin{tabular}{lllll}
\hline Espécie & Concentração energética $\left(\mathrm{MJ} \mathrm{kg}^{-1}\right)$ & Concentração lipídica (\%) & EB $^{\mathrm{a}}\left(\mathrm{MJ} \mathrm{kg}^{-1}\right)$ & Referência \\
\hline Pacu $^{\mathrm{d}}$ & $18,1-21,6 \mathrm{~EB}^{\mathrm{a}}$ & $2,40-8,30$ & -- & Bechara et al. (2005) \\
Pacu $^{\mathrm{d}}$ & $13,1-14,8 \mathrm{ED}^{\mathrm{b}}$ & $3,60-7,80$ & $14,4-17,1$ & Abimorad et al. (2007) \\
Pacu $^{\mathrm{d}}$ & $11,7-14,2 \mathrm{ED}^{\mathrm{b}}$ & $5,30-8,75$ & $18,0-19,0$ & Bicudo et al. (2009) \\
Tambaquie $^{\mathrm{N}}$ & $18,7-22,2 \mathrm{~EB}^{\mathrm{a}}$ & $4,80-20,4$ & $18,7-22,2$ & Van der Meer et al. (1997b) \\
Tambacu $^{\mathrm{b}}$ & $16,0 \mathrm{~EB}^{\mathrm{c}}$ & 5,21 & 15,6 & Macari et al. (1994) \\
Tambacu $^{\mathrm{f}}$ & $15,0-16,6 \mathrm{~EB}^{\mathrm{a}}$ & $0,64-5,94$ & $15,0-16,6$ & Presente estudo
\end{tabular}

a Energia bruta calculada a partir das porcentagens de carboidratos, proteínas e lipídios das dietas, utilizando-se os valores de 17,20; 23,60

e 39,50 MJ para cada kg destes nutrientes, respectivamente (Bureau et al., 2002).

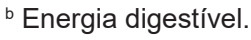

${ }^{c}$ Energia bruta.

qualquer modo, em dietas práticas o P é quase sempre o ingrediente limitante, além de que as fontes convencionais de $\mathrm{P}$ são também fontes de Ca.

Efeitos similares ao observado para o GP ocorreram em relação à TCE e à CA, que também foram menor e pior, respectivamente, para a ração controle 1 em relação às demais. Adicionalmente, a comparação entre

Tabela V. Estimativa dos custos de produção de rações artesanais à base de macaxeira e farelo de soja (valores em $\mathrm{R} \$ \mathrm{~kg}^{-1}$ de ração seca) ${ }^{\mathrm{a}}$. (Production costs approach of the cassava tubercles and soybean meal artisanal feed (values in $\mathrm{R} \$ \mathrm{~kg}^{-1}$ of dry feed) ${ }^{\mathrm{a}}$ ).

\begin{tabular}{|c|c|c|c|c|}
\hline \multirow[t]{2}{*}{ Detalhamento de custos } & \multicolumn{4}{|c|}{ Rações } \\
\hline & Controle & 1 & 2 & 3 \\
\hline Farelo de soja & 1,11 & 1,13 & 1,15 & 1,15 \\
\hline Macaxeira & 0,38 & 0,35 & 0,31 & 0,31 \\
\hline Premix & 0,11 & 0,11 & 0,11 & 0,11 \\
\hline Fosfato bicálcico & --- & 0,09 & 0,09 & 0,09 \\
\hline Óleo de soja & --- & --- & 0,15 & 0,15 \\
\hline DL-metionina & --- & --- & --- & 0,04 \\
\hline Ralador elétrico ${ }^{b}$ & 0,02 & 0,02 & 0,02 & 0,02 \\
\hline Moedor de carne ${ }^{c}$ & 0,07 & 0,07 & 0,07 & 0,07 \\
\hline Secador elétrico ${ }^{d}$ & 0,08 & 0,08 & 0,08 & 0,08 \\
\hline Energia elétrica rural & 0,42 & 0,42 & 0,42 & 0,42 \\
\hline Total & 2,19 & 2,27 & 2,40 & 2,44 \\
\hline Mão-de-obra $\left(\mathrm{h} \mathrm{kg}^{-1}\right)^{\mathrm{e}}$ & 0,13 & 0,13 & 0,13 & 0,13 \\
\hline
\end{tabular}

a Valores referentes a fevereiro de 2018 , município de Mãe-do-Rio, Pará. Custos de transporte de ingredientes não foram considerados.

${ }^{b}$ Ralador artesanal local conectado a motor elétrico de $1,5 \mathrm{cv}$; $\mathrm{R} \$ 800,00$; consumo de $1,1 \mathrm{kwt} \mathrm{h}^{-1}$; vida útil estimada em quatro anos, processando $36 \mathrm{t}$ de macaxeira úmida.

'Beccaro, Rio Claro-SP, modelo PB22, 220 V, R $\$ 1600,00$; consumo de $2,2 \mathrm{kwt} \mathrm{h}^{-1}$; vida útil estimada em quatro anos, processando 48 t de mistura úmida.

d Soprador de ar quente - Leister, modelo Hotwind, $3700 \mathrm{~W}$, $220 \mathrm{~V}$ - acoplado a caixa rústica de madeira medindo $1 \times 1 \times 2 \mathrm{~m}$ $\mathrm{R} \$ 1700,00$; consumo de $1,85 \mathrm{kwt} \mathrm{h}^{-1}$; vida útil estimada em quatro anos, processando 24 t de ração seca.

e Lavagem e ralagem da macaxeira, mistura dos ingredientes, confecção dos grânulos, lavagem do material e ensacamento da ração pronta. as rações 1 e controle 1 (teste t-student), demonstrou novamente o efeito positivo da inclusão de uma fonte de $\mathrm{Pe} \mathrm{Ca}$. As taxas de CA obtidas com as rações 1, 2, 3 e controle 2 podem ser consideradas boas em relação àquelas obtidas no cultivo de diversas espécies, tais como o jundiá, Rhamdia quelen $(1,80)$, e o matrinxã, Brycon cephalus $(1,70)$ (Fracalossi et al., 2004). No entanto, foi maior que aquela observada para o tambaqui $(1,35)$ por Arbeláez-Rojas et al. (2002). Já em relação à TCE, aquelas observadas para os peixes alimentados com as rações 1, 2, 3 e controle 2 estão próximas aos valores encontrados para juvenis de tambaqui por Mendonça et al. (2009), entre 1,13 e 1,45\%, e para juvenis de pacu por Fernandes et al. (2000), entre 1,64 e 1,80\%.

Por outro lado, as TCE's registradas em criações comerciais de tambacu no Nordeste Paraense são próximas a 2,99\%, para peixes entre 10 e $800 \mathrm{~g}$ (Meyer et al., 2009). A partir disso, ressalva-se que há a necessidade de validar os resultados obtidos neste estudo em condições que retratem melhor aquelas das pisciculturas comerciais, ou seja, que permitam a obtenção de maiores TCE's. Neste sentido, nossa hipótese é a de que o tamanho dos tanques utilizados no experimento limitou o crescimento dos peixes. Isto porque é sabido que, além da densidade de estocagem, o tamanho do tanque pode influenciar o desempenho dos peixes, conforme observaram Kadir et al. (2007) e Ranta e Pirhonen (2006) para a carpa, Labeo rohita, e para a truta, Oncorhynchus mykiss, respectivamente, onde os tanques menores afetaram a performance.

As TEP's referentes aos peixes alimentados com as rações 1,2 e 3 foram maiores $(P<0,05)$ em relação àquela obtida com a ração controle 1 , reforçando a necessidade de uso de uma fonte adicional de P e Ca nas rações à base de macaxeira e farelo de soja. Isto porque a comparação entre as rações 1 e controle 1, utilizando-se o teste $\mathrm{t}$-student, foi significativa $(\mathrm{P}<0,001)$. As TEPs dos peixes alimentados com as rações 1, 2 e 3 também foram maiores que a proporcionada pela ração controle 2, o que sugere que a concentração protéica desta última seja excessiva ao tambacu, reforçando os dados de Bechara et al. (2005), Abimorad et al. (2007) e Vidal-Júnior et al. (1998), que apontam para uma exigência protéica de juvenis de tambacu como sendo igual ou menor que $25 \%$ PB. A única referência encontrada na 
literatura referente à TEP do tambacu variou entre 0,50 e 1,23 (Macari et al., 1994), sendo muito inferiores às observadas no presente estudo (entre 2,06 e 2,73).

A inclusão de $4 \%$ de óleo de soja nas rações 2 e 3, e o consequente aumento de suas concentrações energéticas, não foi eficiente na promoção do ganho em peso do tambacu. Segundo Van der Meer et al. (1997b) e Abimorad et al. (2007), tanto o tambaqui como o pacu parecem utilizar fontes lipídicas ou de carboidratos com a mesma eficiência em relação ao GP, entretanto havendo diferenças quanto à deposição de gordura corporal, que aumenta à medida que é aumentada a concentração energética da dieta.

Em consulta à literatura, foi possível observar que a possibilidade de variação da concentração energética das dietas para estas espécies é grande, sem que haja comprometimento do desempenho. Na Tabela IV estão apresentadas concentrações energéticas e lipídicas de dietas experimentais que promoveram os melhores desempenhos para o pacu e o tambacu. A partir dela pode-se inferir que a concentração energética das rações artesanais, com ou sem suplementação de óleo, estiveram dentro da faixa de variação energética para obtenção do melhor desempenho, o que justifica a ausência de diferenças significativas entre as rações 1 e 2 (teste t-student), por sua vez diferenciadas apenas em relação à quantidade de óleo da composição. Com isso, pode-se sugerir que o tambacu, responde de maneira similar às suas espécies de origem e que rações artesanais à base de macaxeira e farelo de soja parecem suprir, além da energia, as exigências em ácidos graxos do tipo n-6. Segundo Vásquez-Torres et al. (2013) este grupo de ácidos graxos é particularmente importante para peixes de água doce, ademais o óleo de soja é uma fonte rica neste nutriente.

Não compreendemos exatamente a razão pela qual os níveis de extrato etéreo revelados pelas análises de composição das dietas experimentais estiveram abaixo da quantidade de óleo acrescida (ver Tabela I). De qualquer modo, mesmo seguindo-se rigorosamente as determinações analíticas da AOAC, é relativamente frequente, no que se refere especificamente aos lipídios, que o resultado da análise seja um pouco inferior ao formulado e/ou à quantidade acrescida na mistura.

O farelo de soja é um ingrediente protéico de origem vegetal amplamente utilizado em rações para peixes pela sua disponibilidade nacional e elevado valor nutritivo. No entanto, é deficiente em aminoácidos sulfurados que, por sua vez, devem estar presentes, em média, na proporção de $3 \%$ da proteína da ração para peixes onívoros (Wilson, 2002). Considerando que não houve diferença significativa para GP, TCE, CA e TEP entre as rações 2 e 3 (teste t-student), a inclusão de 0,2\% de DL-metionina não influenciou o desempenho dos tambacus, sugerindo que a utilização do farelo de soja como única macro fonte protéica é suficiente para atender à exigência por este aminoácido; ou que a velocidade de absorção de sua forma sintética não seja compatível para promover maiores taxas de crescimento, uma vez que sua absorção no trato digestório é mais rápida que proteínas (NRC, 2011; Baldisserotto, 2009). Entretanto, frisa-se que este resultado deve ser validado em experimentos capazes de proporcionar TCEs mais elevadas. Por fim, os dados aqui obtidos reforçam e ampliam os resultados apresentados por Van der Meer (1997a) e Lochmann et al. (2009) que testaram o uso do farelo de soja e da macaxeira na alimentação do tambaqui como principais fontes protéica e energética da dieta, respectivamente.

Em relação à viabilidade econômica das rações experimentais, na Tabela $\mathbf{V}$ estão estimados os custos atualizados dos principais componentes e procedimentos necessário para sua confecção. De modo geral, a ração 1 apresentou custo de produção inferior ao menor preço pago por agricultores familiares na região do Nordeste Paraense (rações com 28\% PB; R\$ 2,40; fev., 2018). Entretanto, tal preço é muito variável na região, fazendo com que a vantagem econômica da adoção da ração artesanal seja relativa. Estimativas de preço adicionais não foram produzidas em função de que os custos de produção familiar no Nordeste Paraense não obedecem estritamente às lógicas mercadológicas. Considerando as lógicas de produção familiar vigente nesta região, seria pouco prudente estimar, por exemplo, o custo da mão-de-obra (influenciada por distintas condições, tais como trabalhos em mutirão, divisão familiar do trabalho, autoconsumo, entre outras). $\mathrm{O}$ preço de venda também é bastante variável, mas situa-se entre $\mathrm{R} \$ 6,00$ e $\mathrm{R} \$$ 8,00, dependendo da época do ano e localidade.

\section{CONCLUSÃO}

Em conclusão, a inclusão de uma fonte adicional de $\mathrm{P}$ e Ca é essencial para que tambacus, alimentados com rações artesanais à base de macaxeira e farelo de soja e premix, obtenham desempenhos similares aos obtidos com rações comerciais extrusadas. A inclusão de DL-metionina e de óleo de soja para o atendimento das exigências em aminoácidos essenciais e energia, respectivamente, não foi necessária nas condições experimentais impostas.

\section{AGRADECIMENTOS}

Os autores agradecem aos Macroprogramas 1 e 6 da Empresa Brasileira de Pesquisa Agropecuária, pelo apoio financeiro à condução da pesquisa concedido por meio dos projetos Aquabrasil e Ver-o-Peixe, respectivamente. Agradecem também ao Laboratório de Agroindústria da Embrapa Amazônia Oriental, pela realização das análises bromatológicas.

\section{BIBLIOGRAFIA}

Abimorad, EG, Carneiro, DJ \& Urbinati, EC 2007, 'Growth and metabolism of pacu (Piaractus mesopotamicus Holmberg 1887) juveniles fed diets containing different protein, lipid and carbohydrate levels', Aquaculture Research, vol. 38, no. 1, pp. 36-44.

AOAC (Association of Official Analytical Chemists) 2000, Official Methods of Analysis. 17a ed. AOAC, Washington.

Arbeláez-Rojas, GA, Fracalossi, DM \& Fim, JDI 2002, 'Composição Corporal de Tambaqui, Colossoma macropomum, e Matrinxã, Brycon cephalus, em Sistemas de Cultivo Intensivo, em Igarapé, e Semi-Intensivo, em Viveiros', Revista Brasileira Zootecnia, vol. 31 , no. 3, pp. 1059-1069. 
Baldisserotto, B 2009, Fisiologia de Peixes Aplicada à Piscicultura, $1^{a}$ ed, Editora da Universidade Federal de Santa Maria, Santa Maria, Brasil.

Bechara, JA, Roux, JP, Díaz, FJR, Quintana, CIF \& Meabe, CAL 2005, 'The effect of dietary protein level on pond water quality and feed utilization efficiency of pacu Piaractus mesopotamicus (Holmberg, 1887)'. Aquaculture Research, vol. 36, pp. 546-553.

Bicudo, AJA, Sado, RY \& Cyrino, JEP 2009, 'Growth and haematology of pacu, Piaractus mesopotamicus, fed diets with varying protein to energy ratio', Aquaculture Research, vol. 40, pp. 486-495.

Bureau, DP, Kaushik, SJ \& Cho, CY 2002, 'Bioenergetics', in JE Halver \& RW Hardy (Orgs.), Fish Nutrition, Academic Press, San Diego, California, pp. 1-59.

Camargo, ACS, Vidal-Júnior, MV, Donzele, JL, Andrade, DR \& Santos, LC 1998, 'Níveis de Energia Metabolizável para Tambaqui (Colossoma macropomum) dos 30 aos 180 gramas de Peso Vivo. 1. Composição das Carcaças', Revista Brasileira de Zootecnia, vol. 27, pp. 409-415.

Fernandez, JBK, Carneiro, DJ \& Sakomura, NK 2000, 'Fontes e Níveis de Proteína Bruta em Dietas para Alevinos de Pacu (Piaractus mesopotamicus)', Revista Brasileira de Zootecnia, vol. 29, pp. 646-653. Fracalossi, DM 2002, 'Brazilian Species', in CD Webster \& CE Lim (Orgs.), Nutrient Requirements and Feeding of Finfish for Aquaculture, CABI Publishing, New York, pp. 389-395.

Fracalossi, DM, Meyer, G, Santamaria, FM, Weingartner, M \& Zaniboni-Filho, E 2004, 'Desempenho do jundiá, Rhamdia quelen, e do dourado, Salminus brasiliensis, em viveiros de terra na região sul do Brasil', Acta Scientiarum - Animal Sciences, vol. 26, pp. 345-352.

Hashimoto, DT, Mendonça, FF, Senhorini, JA, Oliveira, C, Foresti, F, Porto-Foresti, F 2011 , 'Molecular diagnostic methods for identifying Serrasalmid fish (Pacu, Pirapitinga, and Tambaqui) and their hybrids in the Brazilian aquaculture industry', Aquaculture, vol. 321, pp. 49-53.

Kadir, A, Wahab, MA, Miltein, A, Hossain, MA \& Seraji, MTI 2007, 'Effects of silver carp and the small indigenous fish mola Amblypharyngodon mola and punti Puntius sophore on fish polyculture production', Aquaculture, vol. 273, pp. 520-531.

Kubitza, F 2003, Qualidade da água no cultivo de peixes e camarões, $1^{\text {a }}$ ed, Fernando Kubitza, Jundiaí, Brasil.

Lall, SP 2002, 'The minerals', in JE Halver \& RW Hardy (Orgs.), Fish Nutrition, Academic Press, San Diego, California, pp. 259-308.

Lochmann, R, Chen, R, Chu-Koo, FW, Camargo, W, Kohler, CC \& Kasper, C 2009, 'Effects of Carbohydrate-Rich Alternative Feedstuffs on Growth, Survival, Body Composition, Hematology, and Nonspecific Immune Response of Black Pacu, Colossoma macropomum, and Red Pacu, Piaractus brachypomus', Journal of the World Aquaculture Society, vol. 40, pp. 33-44.

Macari, M, Carneiro, DJ, Larson, ML \& Machado, CR 1994, 'Influence of dietary protein intake and recombinant human somatotropin administration on growth and body composition of juvenile tambacu (Piaractus mesopotamicus $\times$ Colossoma macropomum cross) ', Aquaculture, vol. 127, pp. 363-369.

Mendonça, PP, Ferreira, RA, Vidal-Júnior, MV, Andrade, DR, Santos, MVB, Ferreira, AV \& Rezende, FP 2009, 'Influência do fotoperíodo no desenvolvimento de juvenis de tambaqui (Colossoma macropomum)', Archivos de Zootecnia, vol. 58, pp. 323-331.

NRC (National Research Council) 1993, Nutrient requirements of fish, National Academic Press, Washington, D.C.

NRC (National Research Council) 2011, Nutrient requirements of fish and shrimps, National Academies Press, Washington, D.C.

Pezzato, LE, Rosa, MS, Barros, MM \& Guimarães, IG 2006, 'Exigência em fósforo disponível para alevinos de tilápia do Nilo', Ciência Rural, vol. 36, pp. 1600-1605.

Ranta, T \& Pirhonen, J 2006, 'Effect of tank size on food intake and growth in individually held juvenile rainbow trout Oncorhynchus mykiss (Walbaum)', Aquaculture Research, vol. 37, pp. 1381-1385. Sargent, JR, Tocher, DR, Bell, JG 2002, 'The Lipids', in JE Halver \& RW Hardy (Orgs.), Fish Nutrition, Academic Press, San Diego, California, pp. 182-257.

Shao, Q, Ma, J, Xu, Z, Hu, W, Xu, J \& XIE, S 2008, 'Dietary phosphorus requirement of juvenile black seabream, Sparus macrocephalus', Aquaculture, vol. 277, pp. 92-100.

Steel, RGD, Torrie, JH \& Dickey, DA 1997, Principles and procedures of statistics: a biometrical approach, $3^{\mathrm{a}}$ ed, McGraw-Hill, New York.

Tacon, AGJ, Metian, M \& Hasan, MR 2009, Feed ingredients and fertilizers for farmed aquatic animals: Sources and composition, Fisheries and Aquaculture Technical Paper (Vol. 540), FAO, Rome. Tacon, A, Hasan, MR, \& Metian, M 201 1, Demand and supply of feed ingredients for farmed fish and crustaceans. FAO, Rome.

Van der Meer, MB, Faber, R, Zamora, IE \& Verdegem, MCJ 1997a, 'Effect of feeding level on feed losses and feed utilization of soya and fish meal diets in Colossoma macropomum (Cuvier)', Aquaculture Research, vol. 28, pp. 391-403.

Van der Meer, MB, Zamora, IE \& Verdegem, MCJ 1997b, 'Effect of dietary lipid level on protein utilization and the size and proximate composition of body compartments of Colossoma macropomum', Aquaculture Research, vol. 28, pp. 405-417.

Vásquez-Torres, W \& Arias-Castellanos, JA 2013, 'Effect of dietary carbohydrates and lipids on growth in cachama (Piaractus brachypomus)', Aquaculture Research, vol. 44, no. 11, pp. 1768-1776.

Vidal-Júnior, MV, Donzenle, JL, Camargo, ACS, Andrade, DR, Santos, LC 1998, 'Níveis de Proteína Bruta para Tambaqui (Colossoma macropomum), na fase de 30 a 250 gramas. 1. Desempenho dos Tambaquis', Revista Brasileira de Zootecnia, vol. 27, pp. 421-426. Wilson, RP 2002, 'Amino acids and proteins', in JE Halver \& RW Hardy (Orgs.), Fish Nutrition, Academic Press, San Diego, California, pp. 143-179. 